\title{
Otimização do processo de hidrólise do amido de batata (Solanum tuberosum $L$.) cultivar ágata, utilizando enzimas amilolíticas
}

\author{
A. G. T. MENEZES ${ }^{1}$, E. G. T. $\operatorname{MENEZES}^{1}$ e J. G. L. F. ALVES ${ }^{1}$ \\ ${ }^{1}$ Universidade Federal de Lavras, Departamento de Ciência dos Alimentos \\ *E-mail para contato: alinegtm@msn.com
}

\begin{abstract}
RESUMO - A batata (Solanum tuberosum L.) contém cerca de 70 a $80 \%$ de amido em base seca. Pelo alto teor de amido, ela pode ser utilizada em processos fermentativos, para produção de vodca, sendo necessário, entretanto, hidrolisar o amido. O objetivo deste trabalho foi otimizar o processo de hidrólise do amido em relação à concentração de polpa de batata/água, concentração de enzima amiloglicosidase e do tempo de reação. Para isso, foi realizado um delineamento composto central rotacional com um total de 17 tratamentos. As variáveis dependentes analisadas foram a concentração de açúcares redutores $(\mathrm{AR})$ e a eficiência da hidrólise (\%). A concentração de $\alpha$-amilase e seu tempo de reação foram mantidos constantes em 7,5 mL/kg de matéria seca e $2 \mathrm{~h}$. Os resultados demonstraram que a condição ótima para hidrólise foi obtida utilizando pontos máximos para os parâmetros polpa de batata/água $(0,1502$ g matéria seca/g água), concentração de amiloglicosidase (AMG) $(6,5 \mathrm{~mL} / \mathrm{Kg}$ matéria seca) e tempo $(11,04 \mathrm{~h})$. O estudo da otimização da etapa de hidrólise do amido mostrou-se importante para aumentar a produção de açúcares redutores e a eficiência do processo.
\end{abstract}

\section{INTRODUÇÃO}

A batata é uma matéria-prima rica em amido, possuindo em média $65 \%$ a $85 \%$ do peso seco segundo Lajolo e Menezes (2006). De acordo com Food and Agriculture Organization of the United Nations - FAO (2013) a produção mundial de batatas em 2011 foi de 374,4 milhões de toneladas em uma área de, aproximadamente, 19,2 milhões de hectares. O Brasil responde por 3,53 milhões de toneladas (IBGE, 2013). Segundo o IBGE (2013), Minas Gerais é o maior produtor nacional de batatainglesa, com 36,04\% seguido do Paraná (20,77\%), São Paulo (17,68\%), Rio Grande do Sul (10,21\%), Bahia $(6,21)$ e Goiás $(5 \%)$.

Na produção de uma bebida como a vodca, utilizando o amido como fonte de carbono, é necessário o processo de hidrólise deste para obtenção de glicose, maltose e outros açúcares assimiláveis. Essa hidrólise pode ocorrer de duas maneiras, usando-se tratamento ácido ou tratamento enzimático, apresentando esse último vantagens por ser mais seletivo, gastar pouca energia e não gerar produtos indesejáveis (Curvelo-Santana; Ehrhardt; Tambourgui, 2010; Delgado; Castro; Vazquez, 2009).

A hidrólise enzimática pode ser realizada por enzimas amilolíticas como a $\alpha$-amilase e amiloglicosidase em duas etapas: a liquefação e a sacarificação. No processo de liquefação, os grânulos de amido são dispersos em solução aquosa, aquecidos (causando a gelatinização) e 
hidrolisados parcial e irreversivelmente, com auxílio da $\alpha$-amilase que é uma enzima que age apenas nas ligações do tipo $\alpha-1,4-D$-glicosídicas entre as unidades adjacentes de glicose na cadeia linear de amilose (Fennema; Parkin; Damodaran, 2010).

Após a liquefação, a solução de maltodextrina é hidrolisada em glicose por uma enzima desramificante, atuando sobre as ligações glicosídicas $\alpha-1,6$ da amilopectina. $O$ resultado dessa segunda etapa é uma solução de sacarídeos de baixa massa molecular como glicose e maltose.

A concentração de enzimas, o tempo e a proporção de polpa são fatores fundamentais na hidrólise de derivados amiláceos, sendo importante encontrar valores ótimos para essas variáveis para uma hidrólise eficiente (Maarel et al., 2002). A metodologia de planejamento experimental juntamente com a análise de superfície de resposta é uma ferramenta poderosa que fornece informações seguras para determinar condições ótimas do processo (Rodrigues; Iemma, 2009).

Este trabalho foi realizado com o objetivo de otimizar o processo de hidrólise enzimática da polpa de batata visando aumentar a concentração de açúcares fermentescíveis.

\section{MATERIAIS E MÉTODOS}

O trabalho foi conduzido no laboratório de Engenharia de Bioprocessos e Produtos vegetais do Departamento de Ciência dos Alimentos, da Universidade Federal de Lavras.

\subsection{Matéria-prima}

A matéria-prima foi composta por tubérculos de batata (Solanum tuberosum L.), cultivar Ágata, adquirida no comércio local da cidade de Lavras/MG. As batatas foram, inicialmente, lavadas em água corrente, descascadas manualmente e trituradas em liquidificador industrial (Poli modelo LS-06, Brusque/Brasil). Após a trituração, o lote de material foi homogeneizado e armazenado em sacos plásticos de PVC a $-18^{\circ} \mathrm{C}$ até o momento do uso. As amostras foram preparadas, separadamente, em lotes de $1 \mathrm{~kg}$ de batata cada.

\subsection{Enzimas amilolíticas}

Foram utilizadas duas enzimas amilolíticas, a enzima $\alpha$-amilase Termamyl $2 \mathrm{X}$, produzida por cepas de Bacillus licheniformis, que possui atividade enzimática de $240 \mathrm{KNU}-\mathrm{T} / \mathrm{g}$ e a enzima amiloglicosidase AMG 300L, produzida por cepas de Aspergillus niger, cuja atividade enzimática é de $300 \mathrm{AGU} / \mathrm{mL}$, cedidas pela Romerlabs (Campinas/SP).

\subsection{Otimização da hidrólise enzimática}

A matéria-prima processada foi acrescida de água nas proporções referentes ao planejamento experimental (Tabela 1) e transferida para os erlenmeyers. $\mathrm{O} \mathrm{pH}$ foi ajustado para 6,0 e 6,5 utilizando-se $\mathrm{NaOH} 2 \mathrm{~N}$. As amostras foram aquecidas, gradualmente, até $90^{\circ} \mathrm{C}$, em banho-maria com agitação de $150 \mathrm{rpm}$. A temperatura foi mantida por uma hora para a 
gelatinização do amido. Após o tempo de gelatinização, a enzima $\alpha$-amilase (Termamyl 2X) foi adicionada em uma concentração de $7,5 \mu \mathrm{L} / \mathrm{g}$ de massa seca de acordo com metodologia proposta por Pavlak, Abreu-Lima e Carreiro (2011). Os erlenmeyers, contendo as amostras, foram resfriados para $60{ }^{\circ} \mathrm{C}$ e, em seguida, foi realizada a etapa de sacarificação.

A etapa de sacarificação foi investigada, realizando-se um delineamento composto central rotacional (DCCR), com três variáveis independentes (quantidade de amiloglicosidase, a relação de sólido e líquido e tempo de sacarificação), totalizando 17 tratamentos. As variáveis respostas foram concentração de açúcares redutores e eficiência da hidrólise. Os limites das variáveis estão apresentados na Tabela 1 e são semelhantes aos propostos por Duvernay et. al. (2013). Os resultados foram analisados, utilizando o programa Statistica 8.0 (Statsoft, 2008), considerandose um nível de significância de $95 \%$.

Tabela 1 Relação entre valores codificados e reais das variáveis independentes do DCCR

\begin{tabular}{|c|c|c|c|}
\hline Níveis & $\underset{\left(X_{1}\right)}{\text { Amiloglicosidase }^{1}}$ & $\begin{array}{c}\text { Tempo }(h) \\
\left(\mathbf{X}_{2}\right)\end{array}$ & $\begin{array}{c}\text { Sólido/líquido }^{2} \\
\left(\mathbf{X}_{3}\right)\end{array}$ \\
\hline$-1,68$ & 1,5 & 0,96 & 0,0998 \\
\hline-1 & 2,5 & 3,00 & 0,1100 \\
\hline 0 & 4,0 & 6,00 & 0,1250 \\
\hline 1 & 5,5 & 9,00 & 0,1400 \\
\hline 1,68 & 6,5 & 11,04 & 0,1502 \\
\hline
\end{tabular}

$\mathrm{Na}$ etapa de sacarificação, o $\mathrm{pH}$ foi novamente ajustado nas condições ótimas da enzima amiloglicosidase, entre 4,0 e 4,5, utilizando $\mathrm{HCl} 2 \mathrm{~N}$ e a temperatura foi ajustada para $60 \circ \mathrm{C}$. Os tempos de cada hidrólise variaram de acordo com planejamento.

Foram retiradas amostras em triplicata no início da gelatinização (tempo 0h), após a liquefação (tempo 3h) e ao final do tempo da sacarificação proposto para cada tratamento. Para inativação das enzimas, as amostras coletadas foram colocadas em banho de gelo por 5 minutos. As amostras foram centrifugadas (3000 g, $5 \mathrm{~min}$ ) e os sobrenadantes removidos e armazenados a $-18^{\circ} \mathrm{C}$ para as análises de açúcares redutores.

\subsubsection{Análises}

\subsubsection{Açúcares redutores $(\mathrm{AR})$}

As concentrações de AR foram determinadas de acordo com o método DNS (ácido 3,5 dinitrossalicílico), proposto por Miller (1959). Para o cálculo, foram feitas curvas de calibração com glicose.

\subsubsection{Rendimento teórico da hidrólise}


A eficiência do processo foi calculada sobre a quantidade de amido na matéria-prima que entrou no processo. O rendimento teórico da hidrólise (Yteórico) do amido foi obtido pela Equação 1,

$$
\text { Yteórico }=\frac{180 . M}{162 . V}
$$

onde 180 é a massa molecular da glicose (g/mol); 162 é a massa molecular do monômero de glicose na molécula de amido $(\mathrm{g} / \mathrm{mol}) ; \mathrm{M}$ é massa de amido $(\mathrm{g}) ; \mathrm{V}$ é volume de meio $(\mathrm{mL})$.

Considerando os valores de rendimento teórico foi calculada a eficiência da hidrólise pela seguinte Equação 2:

$$
\text { Eficiencia da hidrólise }(\%)=\left(\frac{Y_{\text {real }}}{Y_{\text {teborico }}}\right) \times 100
$$

onde YREAL é o rendimento de açúcares obtido no ensaio (g/L) e YTEÓRICO é o rendimento que seria obtido da hidrólise total da massa de amido $(\mathrm{g} / \mathrm{L})$.

\section{RESULTADOS E DISCUSSÕES}

\subsection{Otimização da hidrólise enzimática}

Para avaliar a influência das variáveis independentes, concentração de amiloglicosidase $\left(\mathrm{X}_{1}\right)$, tempo de hidrólise $\left(\mathrm{X}_{2}\right)$ e proporção polpa de batata e água $\left(\mathrm{X}_{3}\right)$, sobre as variáveis dependentes: AR e eficiência, foi realizado um delineamento composto central rotacional (DCCR). Os resultados obtidos, baseando-se nos 17 experimentos laboratoriais, executados aleatoriamente, encontram-se na Tabela 2.

Analisando-se os resultados, verifica-se que os valores de AR e eficiência da hidrólise variaram bastante, de 59 a $128 \mathrm{~g} / \mathrm{L}$ para AR e de 55,6 a 100\% para eficiência. Em relação à AR e eficiência, pode-se notar que os ensaios 12 e 8 apresentaram os maiores valores para AR e eficiência, $128 \mathrm{~g} / \mathrm{L}$ e $100 \%$, respectivamente. Estes tratamentos possuíam concentrações de 4 e $5,5 \mathrm{~mL} / \mathrm{Kg}$ de massa seca da enzima amiloglicosidase, tempos de hidrólise de 11,04 e $9 \mathrm{~h}$ e proporção sólido/líquido de 0,125 e 0,14 g massa seca/g água, respectivamente. Assim, pode-se notar que baixos valores desses parâmetros provocam menores valores de AR e de eficiência de hidrólise.

$\mathrm{Na}$ análise estatística do planejamento, foram avaliados os efeitos lineares, quadráticos e de interação das variáveis respostas analisadas. Pela análise estatística, foram considerados significativos os parâmetros com p-valor menores que $5 \%(\mathrm{p}<0,05)$. Os termos lineares do modelo matemático estão associados à letra L e os quadráticos à letra $\mathrm{Q}$.

Tabela 2 Resultados experimentais do DCCR expressos em AR (g/L) e Eficiência

\begin{tabular}{llllll} 
Ensaios & Amiloglicosidase & Tempo & Sólido/líquido & AR & Eficiência \\
\hline
\end{tabular}




\section{9 a 22 de outubro de 2014 \\ Florianópolis/SC}

\begin{tabular}{|c|c|c|c|c|c|c|c|c|}
\hline & Cod & $\begin{array}{c}\mathrm{mL} / \mathrm{Kg} \\
\mathrm{ms}\end{array}$ & Cod & horas & Cod & $\mathrm{g} / \mathrm{g}$ & $(g / L)$ & $(\%)$ \\
\hline 1 & -1 & 2,5 & -1 & 3 & -1 & 0,11 & 76,3 & 82 \\
\hline 2 & 1 & 5,5 & -1 & 3 & -1 & 0,11 & 78,9 & 84,7 \\
\hline 3 & -1 & 2,5 & 1 & 9 & -1 & 0,11 & 79,6 & 85,5 \\
\hline 4 & 1 & 5,5 & 1 & 9 & -1 & 0,11 & 80 & 85,9 \\
\hline 5 & -1 & 2,5 & -1 & 3 & 1 & 0,14 & 91,9 & 77,6 \\
\hline 6 & 1 & 5,5 & -1 & 3 & 1 & 0,14 & 65,8 & 55,5 \\
\hline 7 & -1 & 2,5 & 1 & 9 & 1 & 0,14 & 95,1 & 80,3 \\
\hline 8 & 1 & 5,5 & 1 & 9 & 1 & 0,14 & 128,2 & 100 \\
\hline 9 & $-1,68$ & 1,5 & 0 & 6 & 0 & 0,125 & 82,9 & 78,4 \\
\hline 10 & 1,68 & 6,5 & 0 & 6 & 0 & 0,125 & 73,7 & 69,6 \\
\hline 11 & 0 & 4 & $-1,68$ & 0,96 & 0 & 0,125 & 88,9 & 84,1 \\
\hline 12 & 0 & 4 & 1,68 & 11,04 & 0 & 0,125 & 128,3 & 100 \\
\hline 13 & 0 & 4 & 0 & 6 & $-1,68$ & 0,0998 & 59,1 & 69,9 \\
\hline 14 & 0 & 4 & 0 & 6 & 1,68 & 0,1502 & 91,3 & 71,8 \\
\hline 15 & 0 & 4 & 0 & 6 & 0 & 0,125 & 67,1 & 63,4 \\
\hline 16 & 0 & 4 & 0 & 6 & 0 & 0,125 & 64,2 & 60,6 \\
\hline 17 & 0 & 4 & 0 & 6 & 0 & 0,125 & 67,4 & 63,7 \\
\hline
\end{tabular}

AR- Açúcar redutor

Os resultados da análise estatística, para açúcares redutores (Tabela 3), avaliados a 5\% de significância, indicaram que foram significativos os termos linear e quadrático do tempo, o termo linear da proporção sólido/líquido e a interação tempo e proporção sólido/líquido. Como os coeficientes dos termos linear do tempo e da proporção sólido/líquido foram positivos, indicam que um aumento do tempo e da proporção sólido/líquido proporciona aumento na concentração de açúcares redutores no meio. Com relação à interação entre tempo e proporção sólido/líquido, ela foi significativa e positiva.

Ao analisar, estatisticamente, os dados experimentais da eficiência (Tabela 3), a 5\% de significância, foram significativos apenas os coeficientes da variável tempo (termos linear e quadrático), que foram positivos, indicando que quanto maior o tempo de hidrólise, maior a eficiência.

Os resultados da análise de variância (ANOVA) para as respostas AR e eficiência estão descritos nas Tabelas 4 e 5, respectivamente, onde se nota pelo coeficiente de determinação $\left(\mathrm{R}^{2}\right)$ que $90,92 \%$ da variação experimental observada é explicada para AR e 87,06\% da variação experimental é explicada para eficiência. Verifica-se, também, que os valores de F, calculado da regressão, são maiores que os valores de F tabelado a um nível de confiança de 95\%. Desta forma, esses resultados indicam um bom ajuste do modelo aos valores experimentais e previstos pelo modelo.

Tabela 3 Coeficientes das regressões para teor de açúcares redutores e eficiência

AR p-valor Eficiência p-valor




\begin{tabular}{ccccc} 
Média & 66,32728 & 0,000004 & 62,48395 & 0,000001 \\
(1)Amiloglicosidase(L) & $-0,41374^{\mathrm{NS}}$ & 0,870632 & $-1,012695262^{\mathrm{NS}}$ & 0,604543 \\
Amiloglicosidase(Q) & $3,89967^{\mathrm{NS}}$ & 0,191618 & $4,368263881^{\mathrm{NS}}$ & 0,071437 \\
(2)Tempo(L) & 9,97680 & 0,004728 & 5,769620863 & 0,017598 \\
Tempo(Q) & 14,63735 & 0,000982 & 10,75211469 & 0,001219 \\
(3)Sólido/líquido(L) & 8,82685 & 0,008694 & $-1,576588314^{\mathrm{NS}}$ & 0,426560 \\
Sólido/líquido(Q) & $2,80225^{\mathrm{NS}}$ & 0,333551 & $3,263520074^{\mathrm{NS}}$ & 0,156792 \\
1L por 2L & $7^{\mathrm{N}} 12695^{\mathrm{NS}}$ & 0,061139 & $4,931896335^{\mathrm{NS}}$ & 0,082927 \\
1L por 3L & $0,49163^{\mathrm{NS}}$ & 0,882183 & $-0,692007598^{\mathrm{NS}}$ & 0,784874 \\
2L por 3L & 7,64191 & 0,048231 & $5,300609789^{\mathrm{NS}}$ & 0,066342 \\
$\mathrm{R}^{2}$ & 90,92 & & 87,06 & \\
\hline
\end{tabular}

*NS= Não significativo a 5\% de significância

Tabela 4 Análise de variância para açúcares redutores (AR)

\begin{tabular}{ccccc}
\hline $\begin{array}{c}\text { Fonte de } \\
\text { variação }\end{array}$ & $\begin{array}{c}\text { Graus de } \\
\text { liberdade }\end{array}$ & $\begin{array}{c}\text { Soma dos } \\
\text { quadrados }\end{array}$ & $\begin{array}{c}\text { Quadrado } \\
\text { médio }\end{array}$ & Fcalc \\
\hline Regressão & 9 & 5735,760 & 637,3066174 & 7,78 \\
Erro & 7 & 572,946 & 81,84941631 & \\
Total & 16 & 6308,705 & & \\
\hline \% variação explicada $\left(\mathrm{R}^{2}\right)=90,92 \%$ & $\mathrm{~F}_{9 ; 7 ; 0,05}=3,68$ & &
\end{tabular}

Tabela 5 Análise de variância para eficiência

\begin{tabular}{ccccc}
\hline $\begin{array}{c}\text { Fonte de } \\
\text { variação }\end{array}$ & $\begin{array}{c}\text { Graus de } \\
\text { liberdade }\end{array}$ & $\begin{array}{c}\text { Soma dos } \\
\text { quadrados }\end{array}$ & $\begin{array}{c}\text { Quadrado } \\
\text { médio }\end{array}$ & Fcalc \\
\hline Regressão & 9 & 2243,248 & 249,2497576 & 5,23 \\
Erro & 7 & 333,273 & 47,61044985 & \\
Total & 16 & 2576,521 & & \\
\hline \% variação explicada $\left(\mathrm{R}^{2}\right)=87,06 \%$ & $\mathrm{~F}_{9 ; 7 ; 0,05=3,68} 3$ & &
\end{tabular}

A curva de contorno para o teor de açúcares redutores (Figura 1) apresenta os efeitos da proporção sólido/líquido e do tempo sobre AR, com a dosagem enzimática fixada no ponto máximo $(6,5 \mathrm{~mL} / \mathrm{Kg}$ massa seca), com maiores concentrações de açúcares redutores obtidas na região de maior tempo de hidrólise e maior proporção sólido/líquido. 


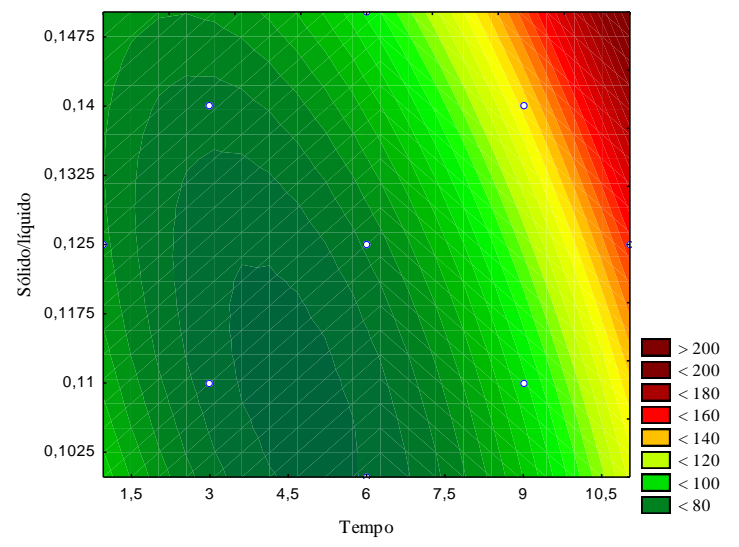

Figura 1 Curva de contorno para o teor de açúcares redutores, sendo a concentração de amiloglicosidase fixada no ponto máximo $(6,5 \mathrm{~mL} / \mathrm{Kg}$ matéria seca).

$\mathrm{Na}$ curva de contorno para eficiência do processo de hidrólise (Figura 2), estão apresentados os efeitos da proporção sólido/líquido e do tempo, com a dosagem enzimática fixada no ponto máximo $(6,5 \mathrm{~mL} / \mathrm{Kg}$ massa seca). As maiores eficiências são obtidas na região de elevadas proporções sólido/líquido e maiores tempos de hidrólise. Sendo assim, com base nos resultados das curvas de contorno para açúcares redutores e eficiência, pode-se notar que maiores concentrações de enzimas, proporção sólido/líquido e maior tempo ocasionarão melhores condições de hidrólise, ou seja, maior eficiência na quebra de amido em açúcares.

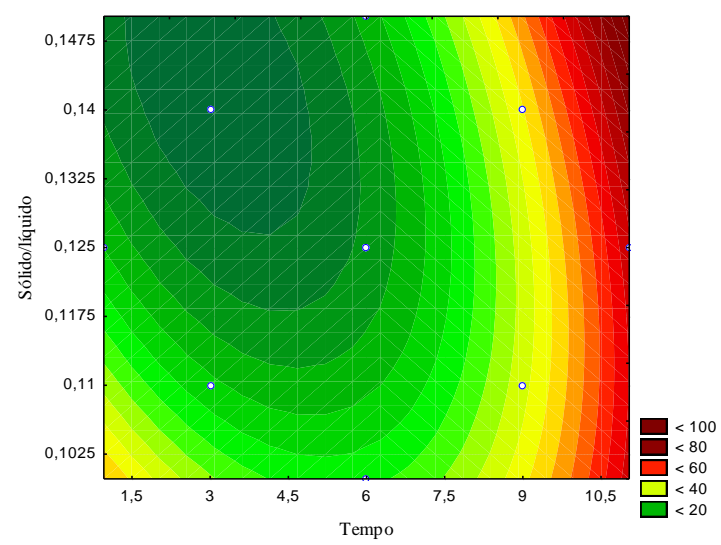

Figura 2 Curva de contorno para eficiência do processo de hidrólise, sendo a concentração de amiloglicosidase fixada no ponto máximo $(6,5 \mathrm{~mL} / \mathrm{Kg}$ matéria seca).

\section{CONCLUSÃO}

Foram obtidos bons resultados de conversão de amido em açúcares, com concentração de AR de 128 g.L L $^{-1}$ e eficiência de hidrólise de $100 \%$ usando concentração de amiloglicosidase de 
$6,5 \mathrm{~mL} / \mathrm{Kg} \mathrm{MS}$, proporção polpa/água de 0,1502 g MS/g e tempo de hidrólise de 11,04 h. Conclui-se, portanto, que o amido da batata pode ser eficientemente hidrolisado por tratamento enzimático com $\alpha$-amilase e amiloglicosidase, visando posterior etapa de fermentação alcoólica.

\section{REFERÊNCIAS}

CURVELO-SANTANA, J. C.; EHRHARDT, D. D.; TAMBOURGUI, E. B. Otimização da produção de álcool de mandioca. Ciência e Tecnologia de Alimentos, Campinas, v. 30, n. 3, p. 613-617, jul./set. 2010.

DELGADO, R.; CASTRO, A. J.; VAZQUEZ, M. A kinetic assessment of the enzymatic hydrolysis of potato (Solanum tuberosum). LWT - Food Science and Technology, Trivandrum, v. 42, n. 4, p. 797-804, 2009.

DUVERNAY, W. H.; CHINN, S. M.; YENCHO, G. C. Hydrolysis and fermentation of sweet potatoes for production of fermentable sugars and ethanol. Industrial Crops and Products, London, v. 42, p. 527-537, Mar. 2013.

FENNEMA, O. R.; PARKING, L. K.; DAMODARAN, S. Química de alimentos de Fennema. 4. ed. Porto Alegre: Artmed, 2010. 900 p

INSTITUTO BRASILEIRO DE GEOGRAFIA E ESTATÍSTICA. Levantamento sistemático da produção agrícola. Rio de Janeiro, 1999. Disponível em: <http://biblioteca.ibge.gov.br/visualizacao/monografias/GEBIS\%20\%20RJ/endef/1999_Tabela\% 20d\%20composicao\%20de\%20alimentos.pdf>. Acesso em: 17 dez. 2013.

LAJOLO, F. M.; MENEZES, E. W. Carbohidratos en alimentos regionales Iberoamericanos. Revista Brasileira de Ciências Farmacêuticas, São Paulo, v. 42, n. 4, p. 648, 2006.

MAAREL, M. J. E. C. et al. Properties and applications of starch-converting enzymes of the $\alpha$ amylase family. Journal of Biotechnology, Amsterdam, v. 94, n. 28, p. 137-155, Mar. 2002.

PAVLAK, M. C. M.; ABREU-LIMA, T. L.; CARREIRO, S. C. Estudo da fermentação do hidrolisado de batata-doce utilizando diferentes linhagens de Saccharomyces cerevisiae. Química Nova, São Paulo, v. 34, n. 1, p. 82-86, nov. 2011.

RODRIGUES, M. I.; IEMMA, A. F. Planejamento de experimentos e otimização de processos. Campinas: Casa do Pão, 2009.

STATSOFT. Statistica: data analysis software systems. Version 8.0. Tulsa, 2008. Software. 